\title{
Leukaemia mortality in relation to magnetic field exposure: findings from a study of United Kingdom electricity generation and transmission workers, 1973-97
}

\author{
J M Harrington, L Nichols, T Sorahan, M van Tongeren
}

\begin{abstract}
Objective-To investigate whether risks of leukaemia are related to occupational exposure to magnetic fields.

Methods-The mortality experienced by a cohort of 83997 employees of the former Central Electricity Generating Board of England and Wales was investigated for the period 1973-97. All employees were employed for at least 6 months with some employment in the period 1973-82. Computerised work histories were available for 79972 study subjects for the period 197193. Detailed calculations were performed by others to enable a novel assessment to be made of exposures to magnetic fields. Two analytical approaches were used, indirect standardisation $(n=83$ 997) and Poisson regression $(n=79$ 972).

Results-Based on serial mortalities for England and Wales, the standardised mortality ratio of 84 for all leukaemias (observed 111, expected 132.3) was similar to that of 83 for all causes (observed 14845 , expected 17 918). No significant positive trends were found for the risks of various types of leukaemia (chronic lymphatic leukaemia, acute myeloid leukaemia, chronic myeloid leukaemia, all leukaemia) either with lifetime cumulative exposure to magnetic fields or with such exposures received in the most recent 5 years.

Conclusions-There are no discernible excess risks of leukaemia as a consequence of occupational exposure to magnetic fields in United Kingdom electricity generation and transmission workers. (Occup Environ Med 2001;58:307-314)
\end{abstract}

Keywords: magnetic fields; leukaemia; electricity generation and transmission; cohort mortality study

Institute of

Occupational Health,

University of

Birmingham,

Edgbaston,

Birmingham B15 2TT,

UK

J M Harrington

L Nichols

T Sorahan

$M$ van Tongeren

Correspondence to:

T M Sorahan

T.M.Sorahan@bham.ac.uk

Accepted 15 January 2001 studies have now been reported which have investigated risks of brain tumours and leukaemia in "electrical and electronic" workers.
Also, large scale cohort mortality studies have been carried out on electric utility workers. ${ }^{3-7}$ Several literature reviews are available. ${ }^{8-10}$

The study described in this report seeks to obtain important new information on the topic of occupational exposure to magnetic fields and risks of leukaemia by examining data from an ongoing epidemiological study of electricity generation and transmission workers from the former Central Electricity Generating Board (CEGB) of England and Wales. The mortality study (based on the national epidemiology file or NEF) was initiated by the CEGB in 1975; responsibility for maintaining and analysing the study passed to the successor companies of the CEGB which came into being after the privatisation of the industry in 1990 . The study has been used previously to investigate occupational exposure to magnetic fields relative to mortality from brain cancer. ${ }^{6}$

\section{Materials and methods}

STUDY POPULATION

The cohort made available for analysis comprised 83997 employees (72 954 men and 11043 women) of the former CEGB for whom computerised information was available. All employees were known to have been employed for at least 6 months with some period of employment in the period 1973-82. (The date of computerisation was different for different regions. Consequently, the file does not include details of all employees with some period of employment in the stated period.) The study computer files comprised "header" records (one record per subject) showing identifying particulars (name, date of birth, national insurance number) together with dates of starting and leaving employment with the CEGB, and 304522 work history records from the NEF (variable number per study subject) showing national insurance numbers, dates of working, and coded entries for job title, region, facility, and negotiating body (pay and conditions) for employment in the period 1971-84. Also, for those subjects still employed in the industry at the start of 1985, a further 44980 computerised work history records for the period 1985-93 were derived from contemporaneous personnel records known as computerised personnel information system (CPIS) data. Later dates of leaving employment were obtained from recent requests to the pensions and human resources departments of all the successor companies. 
The 349502 work history records were found to relate to 79972 study subjects; work histories were not available for the remaining 4025 study subjects. The eight region codes related to the following regions and national divisions of the CEGB: South East, South West, Midlands, North East, North West, generation design and construction (GDCD), transmission and technical services (TTSD), and headquarters (HQ). Details of region were missing for 67726 work history records. For individuals with missing codes, known codes for later periods of working were assumed to apply. Codes for earlier periods were used if later values were unavailable. This procedure enabled the region to be coded for all but 742 work history records.

The negotiating body code related to five employee groups: the National Joint Managerial (NJM) represented managers, the National Joint Board (NJB) represented engineers and scientists, the National Joint Council (NJC) represented administrative and clerical workers, the National Joint Industrial Council (NJIC) represented industrial workers, and the National Joint Building and Civil Engineering Committee $(\mathrm{NJ}(\mathrm{B}+\mathrm{CE}) \mathrm{C})$ represented construction and building workers. The negotiating body was missing for 47741 work history records. It was unusual for employees to change negotiating body. Consequently, for people with missing codes, known codes for later periods of working were assumed to apply. Codes for earlier periods were used if later values were unavailable. This procedure enabled the negotiating body to be coded for all but 421 work history records.

Facility codes (specific power stations, transmission districts, etc) were problematic in that each region had its own set of codes, codes changed over time, and complete contemporaneous lists were no longer available. Satisfactory decoding was made possible by linking $\mathrm{NEF}$ data (work histories in the period 1971-84) with relevant CPIS data. The CPIS data were only available for those employed after 1 January 1985, but for these employees, all earlier periods of employment with the CEGB were described in full text form. These text entries were cross referenced with the corresponding NEF codes for subjects with periods of employment described in both databases. This procedure enabled the facility to be recognised for all but 19073 (5.5\%) work history records. (The CPIS data before 1985 have only been used to help understand the NEF data; they do not feature in later analyses.)

The study received follow up particulars from the National Health Service Central Register (NHSCR) of the Office for National Statistics (ONS). Underlying cause and multiple cause coding had been supplied by the ONS for all deaths (ICD-8 1973-78, ICD-9 197997). A total of $834(1.0 \%)$ subjects had emigrated and $1720(2.1 \%)$ were untraced. For decedents with any mention of leukaemia on the death certificate, confirmation of leukaemia diagnosis was sought from corresponding cancer registration data obtained from the ONS.
ESTIMATION OF EXPOSURE TO MAGNETIC FIELDS Occupational exposures to the high magnetic fields encountered in parts of the United Kingdom electricity generation and transmission industry have been assessed recently by the EMF research section of the National Grid Company. Full details are available elsewhere, ${ }^{11}$ but the protocol may be summarised as follows.

A list was developed showing all power stations, transmission districts, substations and non-operational sites open sometime between 1972 and 1993. Workers at non-operational sites (central and regional headquarters, design and research centres, control centres) were considered to be unexposed to increased levels of occupational magnetic fields.

At power stations, the primary source of magnetic field is the very large current flowing in the generator main connections, which link each generator to its step up transformer. The generator main connections usually comprise three separated conducting bars (busbars) carrying current. At the oldest stations, cables in bundles are used instead; these produce much lower magnetic fields because of the high degree of cancellation. Since about 1968 isolated phase busbars (IPBs) have been used; the three busbars are enclosed by cylindrical sheaths in such a way as to partially screen the magnetic field. At some power stations, nearby overhead lines are also a source of exposure to magnetic fields.

Each power station was classified by the power rating of the generators and by the type of generator main connection (category A generators rated $100 \mathrm{MW}$ or more with busbars; category B generators rated 30-90 MW with busbars; category C generators with cables). Site plans were obtained for each of the category A power stations and a calculated field was derived for each of the main areas of the power station (control room, workshop or stores, administration building, turbine hall, boiler house (conventional power station only), reactor building (nuclear power station only), materials handling), on the basis of its distance from the generator main connections, assuming maximum output from the station (table 1). Site plans were not available for most category B power stations, and a standard site layout was assumed to apply to each of these stations. Workers at category $\mathrm{C}$ power stations were considered to be unexposed to increased levels of magnetic field; site plans were not sought for these power stations.

In general, power stations do not operate at maximum output all of the time, and load factors were obtained for all category $A$ and category B power stations for each financial year (table 1). The calculated field for an area of a power station in a specified financial year is thus given by the product of the relevant load factor and the calculated field assuming maximum output.

For power station workers, 11 work categories were identified based on different patterns of working in the various areas of conventional, nuclear, and pumped storage power stations (table 2). A job dictionary was produced for 
power station employees, showing alphabetical listings of all unique job titles for each negotiating body. Each of the resulting 8544 entries was assessed by a former senior engineer of the CEGB and classified under one of the 11 working pattern headings (personal communication). A further listing of job titles (with negotiating bodies) shown alphabetically

Table 1 Calculated magnetic fields in different areas of category $A$ power stations together with load factors by financial year: sample of data

\begin{tabular}{|c|c|c|c|c|c|}
\hline & \multicolumn{5}{|c|}{ Power station No } \\
\hline & 1 & 7 & 24 & 62 & 63 \\
\hline \multicolumn{6}{|c|}{ Calculated field $(\mu \mathrm{T})$ in areas of power station assuming maximum output: } \\
\hline Control room & 0.67 & 0.51 & 0.02 & 21.77 & 0.11 \\
\hline Workshop, stores & 0.08 & 0.02 & 0.02 & 2.08 & 0.34 \\
\hline Administration building & 0.73 & 0.05 & 0.02 & 0.33 & 0.27 \\
\hline Turbine hall & 11.72 & 5.42 & 1.68 & 24.42 & 13.31 \\
\hline Boiler house & 0.24 & 0.16 & 0.06 & 0.52 & NA \\
\hline Reactor building & $\mathrm{NA}^{\star}$ & NA & NA & NA & 0.08 \\
\hline Materials handling & 0.01 & 0.00 & 0.01 & 0.01 & 0.08 \\
\hline \multicolumn{6}{|l|}{ Load factort: } \\
\hline $1952-53$ & 一 & - & - & - & - \\
\hline $1953-54$ & - & - & - & - & - \\
\hline $1954-55$ & - & - & - & - & - \\
\hline $1955-56$ & - & - & - & - & - \\
\hline $1968-69$ & 0.72 & 0.64 & - & 0.35 & 0.58 \\
\hline $1969-70$ & 0.73 & 0.61 & - & 0.41 & 0.56 \\
\hline $1970-71$ & 0.58 & 0.53 & 0.25 & 0.39 & 0.61 \\
\hline $1971-72$ & 0.66 & 0.39 & 0.40 & 0.41 & 0.65 \\
\hline $1972-73$ & 0.62 & 0.45 & 0.50 & 0.45 & 0.45 \\
\hline $1989-90$ & 0.61 & 0.49 & 0.19 & 0.75 & 0.46 \\
\hline 1990-91 & 0.55 & 0.23 & 0.13 & 0.64 & 0.43 \\
\hline 1991-92 & 0.60 & 0.12 & 0.03 & 0.66 & 0.45 \\
\hline $1992-93$ & 0.56 & 0.02 & 0.01 & 0.74 & 0.41 \\
\hline 1993-94 & 0.14 & 0.00 & 0.02 & 0.67 & 0.50 \\
\hline
\end{tabular}

$\star \mathrm{NA}=$ not applicable, area not present in that power station.

$\dagger 1=$ Maximum output, $0=$ no output.

$\ddagger$ Power station not in operation during that financial year (1 April-31 March).

Table 2 Estimated percentage of working day spent in different parts of the power station for different categories of work

\begin{tabular}{|c|c|c|c|c|c|c|c|c|c|c|c|}
\hline \multirow[b]{2}{*}{ Area in power station } & \multicolumn{11}{|c|}{ Work category ${ }^{\star}$} \\
\hline & 1 & 2 & $3 a$ & $3 b$ & $3 c$ & $4 a$ & $4 b$ & $4 c$ & $5 a$ & $5 b$ & 6 \\
\hline \multicolumn{12}{|c|}{ Conventional power station: } \\
\hline Control room & - & - & - & - & - & - & - & - & 95 & 55 & - \\
\hline Workshop or stores & - & - & 25 & 25 & 85 & 20 & 10 & 65 & - & 5 & 10 \\
\hline $\begin{array}{l}\text { Administration } \\
\text { offices }\end{array}$ & 75 & 100 & 20 & 5 & 15 & 65 & 75 & 15 & 5 & 5 & 50 \\
\hline Turbine hall & 5 & - & 10 & - & - & 5 & - & - & - & 15 & 5 \\
\hline Boiler house & 5 & - & 35 & 10 & - & 5 & 5 & 20 & - & 20 & 5 \\
\hline Materials handling & - & - & 10 & 60 & - & 5 & 10 & - & - & - & - \\
\hline Off site & 15 & - & - & - & - & - & - & - & - & - & 30 \\
\hline \multicolumn{12}{|l|}{ Nuclear power station: } \\
\hline Control room & - & - & - & - & - & - & - & - & 95 & 55 & - \\
\hline Workshop or stores & - & - & 25 & 25 & 85 & 20 & 10 & 65 & - & 5 & 10 \\
\hline $\begin{array}{l}\text { Administration } \\
\text { offices }\end{array}$ & 75 & 100 & 20 & 5 & 15 & 65 & 75 & 15 & 5 & 5 & 50 \\
\hline Turbine hall & 5 & - & 10 & - & - & 5 & - & - & - & 15 & 5 \\
\hline Reactor building & 5 & - & 45 & 70 & - & 10 & 15 & 20 & - & 20 & 5 \\
\hline Off site & 15 & - & - & - & - & - & - & - & - & - & 30 \\
\hline \multicolumn{12}{|l|}{ Pumped storage: } \\
\hline Control room & - & - & - & - & - & - & - & - & 95 & 55 & - \\
\hline Workshop or stores & - & - & 10 & - & 100 & 5 & - & - & 5 & 10 & 10 \\
\hline $\begin{array}{l}\text { Administration } \\
\text { offices }\end{array}$ & 75 & 100 & 5 & - & - & 70 & - & - & - & 一 & 50 \\
\hline Turbine hall & 10 & - & 70 & - & - & 10 & - & - & - & 20 & 5 \\
\hline Other areas & - & - & 15 & - & - & 15 & - & - & - & 15 & 5 \\
\hline Off site & 15 & - & - & - & - & - & - & - & - & - & 30 \\
\hline
\end{tabular}

$\star 1=\mathrm{NJM}$-managerial staff.

$2=$ NJC, NJB and NJIC-administrative and clerical staff.

$3 \mathrm{a}=\mathrm{NJIC}$-industrial staff, main plant (excluding control room).

$3 \mathrm{~b}=\mathrm{NJIC}$ - industrial staff, materials handling.

$3 \mathrm{c}=\mathrm{NJIC}$ - industrial staff, stores.

$4 \mathrm{a}=\mathrm{NJB}$ - engineering staff, main plant (excluding control room).

$4 \mathrm{~b}=\mathrm{NJB}$ - engineering staff, materials handling.

$4 \mathrm{c}=\mathrm{NJB}$ - engineering staff, laboratory.

$5 \mathrm{a}=\mathrm{NJB}$ and NJIC - control room staff working mainly in the control room.

$5 \mathrm{~b}=\mathrm{NJB}$ and NJIC - control room staff based in control room but also visiting other parts of plant. $6=$ Other staff. for each of the 11 working patterns was then produced and the classifications were assessed for consistency; a few changes were made.

For transmission workers recent survey measurements on 93 staff monitored for 1 week were used to estimate exposures for eight categories of substation and transmission line workers (table 3 ). These exposures were based on the surveyed field levels in eight locations (overhead line on the tower, overhead line on the ground, substation high voltage compound, home substation other than high voltage compound, away substation other than high voltage compound, transmission district home office, transmission district away office, and travelling by road) and estimates of the time spent in each of these different working areas by workers in each of the eight occupational categories. These estimates were assumed to apply to all periods.

The coded job histories of each study subject were then cross referenced with the exposure assessments to obtain individual assessments of exposure to magnetic fields for the period April 1952 to March 1994. Cumulative occupational lifetime exposures and cumulative exposures in the most recent 5 years were developed for each study subject, as time dependent variables. Software, written in BASIC, was developed to calculate, for each study subject, if and when any of the predetermined cut off values for exposure levels were reached. The two sets of four cut off values were selected after reviewing the cumulative exposure distributions for deaths from all causes, and before the calculation of any relative risks. Lifetime and recent exposure categories were based on convenient multiples of $2.5 \mu$ T.y and $0.5 \mu$ T.y, respectively. For subjects with employment before 1971, the first known employment details were assumed to apply to the earlier employment.

\section{EXTERNAL STANDARD: STANDARDISED}

MORTALITY RATIO

The mortality experience of the total study cohort $(n=83$ 997) from both all causes and leukaemia was compared with that which might have been expected to occur if rates of mortality for the general population of England and Wales had been operating on the study cohort, having due regard to the composition of the study cohort by sex, age (5 year age groups), and calendar year (5 year calendar periods). Expectations based on person-years at risk were calculated with the PERSONYEARS computer program. ${ }^{12}$ People entered the person-years at risk at the end of the first 6 months of employment or the date of computerisation for the relevant region, whichever was the later. The computerisation date was selected to be 1 January 1977 for all regions except the Midlands (1 January 1973), GDCD (1 January 1975), North West (1 January 1975), and TTSD (1 January 1979), on the basis that these dates were consistent with the regional distributions of dates of leaving employment and dates of death. People left the person-years at risk on the date of death, date of embarkation, date last known alive, or the 
closing date of the study (31 December 1997), whichever was the earlier. People were censored on reaching their 85 th birthday-that is, they make no further contributions to expected or observed numbers past this age.

Standardised mortality ratios (SMRs) were calculated as the ratio of observed to expected

Table 3 Estimates of mean occupational magnetic field exposure for transmission workers

\begin{tabular}{ll}
\hline Employment categories & $\begin{array}{l}\text { Estimates of mean } \\
\text { magnetic field } \\
\text { exposures }(\mu T)\end{array}$ \\
\hline All staff at transmission district offices which are distant from power lines & 0.0 \\
Clerical and engineering staff at transmission district offices which are close & 0.76 \\
$\quad$ to power lines & 0.45 \\
Managers at transmission district offices which are close to power lines & 3.34 \\
Substation linesmen & 1.84 \\
Industrial staff at higher field substations (excluding linesmen) & 1.51 \\
Engineers at higher field substations & 1.41 \\
Industrial staff at lower field substations (excluding linesmen) & 0.83 \\
Engineers at lower field substations &
\end{tabular}

*In excess of background exposure.

Table 4 Study of United Kingdom electricity generation and transmission workers: distribution of deaths and person-years at risk for study subjects with work histories ( $n=79$ 972), 1973-97

\begin{tabular}{|c|c|c|c|c|c|}
\hline & $\begin{array}{l}\text { Chronic } \\
\text { lymphatic } \\
\text { leukaemia } \\
(C L L)^{\star}\end{array}$ & $\begin{array}{l}\text { Other } \\
\text { leukaemiat }\end{array}$ & $\begin{array}{l}\text { All } \\
\text { leukaemia } \neq\end{array}$ & $\begin{array}{l}\text { All other } \\
\text { causesS }\end{array}$ & $\begin{array}{l}\text { Person-years } \\
\text { at risk }\end{array}$ \\
\hline \multicolumn{6}{|c|}{ Estimated cumulative exposure to magnetic fields ( $\mu \mathrm{T} . \mathrm{y})$ : } \\
\hline $0-2.4$ & 21 & 39 & 60 & 6090 & 930589 \\
\hline $2.5-4.9$ & 3 & 15 & 18 & 1581 & 164656 \\
\hline $5.0-9.9$ & 5 & 15 & 20 & 2570 & 220076 \\
\hline $10.0-19.9$ & 7 & 10 & 17 & 2246 & 174386 \\
\hline$\geqslant 20.0$ & 3 & 6 & 9 & 701 & 73404 \\
\hline \multicolumn{6}{|l|}{ Age: } \\
\hline $15-19$ & 0 & 0 & 0 & 22 & 15176 \\
\hline $20-24$ & 0 & 0 & 0 & 28 & 54700 \\
\hline $25-29$ & 0 & 1 & 1 & 43 & 98219 \\
\hline $30-34$ & 0 & 2 & 2 & 81 & 140873 \\
\hline $35-39$ & 0 & 2 & 2 & 153 & 167227 \\
\hline $40-44$ & 0 & 8 & 8 & 229 & 177060 \\
\hline $45-49$ & 0 & 6 & 6 & 457 & 182771 \\
\hline $50-54$ & 1 & 8 & 9 & 860 & 186126 \\
\hline $55-59$ & 3 & 12 & 15 & 1534 & 181532 \\
\hline $60-64$ & 6 & 10 & 16 & 2365 & 156070 \\
\hline $65-69$ & 12 & 17 & 29 & 2894 & 112349 \\
\hline $70-74$ & 10 & 12 & 22 & 2492 & 62212 \\
\hline $75-79$ & 6 & 5 & 11 & 1478 & 23429 \\
\hline $80-84$ & 1 & 2 & 3 & 552 & 5367 \\
\hline \multicolumn{6}{|l|}{ Sex: } \\
\hline Male & 37 & 75 & 112 & 12536 & 1363200 \\
\hline Female & 2 & 10 & 12 & 652 & 199911 \\
\hline \multicolumn{6}{|l|}{ Calendar period: } \\
\hline $1973-79$ & 3 & 5 & 8 & 1264 & 277664 \\
\hline $1980-84$ & 5 & 17 & 22 & 2223 & 375844 \\
\hline $1985-89$ & 7 & 29 & 36 & 3121 & 366254 \\
\hline $1990-97$ & 24 & 34 & 58 & 6580 & 543349 \\
\hline \multicolumn{6}{|c|}{ Year of starting employment: } \\
\hline$<1946$ & 3 & 3 & 6 & 740 & 31667 \\
\hline $1946-64$ & 19 & 33 & 52 & 6394 & 458199 \\
\hline $1965-72$ & 9 & 29 & 38 & 4116 & 486891 \\
\hline$\geqslant 1973$ & 8 & 20 & 28 & 1938 & 586354 \\
\hline \multicolumn{6}{|c|}{ Period from first employment $(\mathrm{y})$ : } \\
\hline $0-9$ & 1 & 5 & 6 & 752 & 351041 \\
\hline $10-19$ & 8 & 29 & 37 & 2961 & 568945 \\
\hline $20-29$ & 11 & 26 & 37 & 4392 & 398686 \\
\hline$\geqslant 30$ & 19 & 25 & 44 & 5083 & 244439 \\
\hline \multicolumn{6}{|l|}{ Employment status $\uparrow:$} \\
\hline Still employed & 2 & 19 & 21 & 2174 & 674132 \\
\hline Left employment & 37 & 66 & 103 & 11014 & 888979 \\
\hline \multicolumn{6}{|c|}{ Negotiating body (pay and conditions): } \\
\hline NJM & 1 & 0 & 1 & 133 & 10960 \\
\hline NJB & 5 & 16 & 21 & 1820 & 354839 \\
\hline NJC & 6 & 12 & 18 & 1200 & 252053 \\
\hline NJIC & 26 & 55 & 81 & 9808 & 929972 \\
\hline $\mathrm{NJ}(\mathrm{B}+\mathrm{C}) \mathrm{E}$ & 1 & 2 & 3 & 210 & 13725 \\
\hline Not known & 0 & 0 & 0 & 17 & 1562 \\
\hline Total & 39 & 85 & 124 & 13188 & 1563111 \\
\hline
\end{tabular}

*Any part of death certificate coded to ICD-9 204.1.

†Any part of death certificate coded to ICD-9 204-208, excluding ICD-9 204.1.

$¥$ Any part of death certificate coded to ICD-9 204-208.

$\S$ No part of death certificate coded to ICD-9 204-208.

ๆSubjects enter person-years at risk for left employment category 3 months after date of leaving. numbers of deaths expressed as a percentage. In calculating $\mathrm{p}$ values and confidence intervals (95\% CIs), it was assumed that deaths occur as a Poisson process. Any significance tests were two tailed.

INTERNAL STANDARD: POISSON REGRESSION

Eight variables were considered to have the potential for influencing mortality within the subcohort for which work history data were available ( $n=79$ 972): attained age, sex, calendar year, year of starting employment with the CEGB, employment status (still employed or left employment), estimated exposure to magnetic fields (each exposure metric considered in turn), period from first employment, and negotiating body (surrogate for socioeconomic group). These variables were not treated as continuous variables, but rather each variable was categorised into a number of levels (table 4). In constructing the models, it was necessary to ensure that there was at least one death observed at each level of each variable. All adjustments were made before any statistical modelling was carried out. The analysis allowed for subjects to contribute person-years at risk to contemporaneous categories.

The EPICURE computer program ${ }^{13}$ was used to provide both person-years at risk (as defined previously) and numbers of deaths for various types of leukaemia (any mention on the death certificate) and for all other causes, for all combinations of all levels of the variables (table 4). The EPICURE program was also used to carry out statistical modelling by means of Poisson regression. ${ }^{14}$ The purpose of the modelling was to provide point estimates of rate ratios (relative risks) for each category of exposure to magnetic fields compared with the baseline (lowest) category, with and without adjustment for other variables. More importantly, the significance of any trend in risk across the exposure categories was assessed by repeating the analysis while treating exposure as a single variable. The five exposure categories were first scored $1-5$ to calculate a linearly weighted $\mathrm{p}$ value for trend. Information on the estimated cumulative exposure for each study subject at the end of each financial year was used to calculate mean exposures for the person-years at risk in each of the five exposure categories. These mean exposures were then used to calculate a dose weighted $\mathrm{p}$ value for trend.

\section{Results}

STANDARDISED MORTALITY RATIOS

Observed and expected numbers of deaths for all leukaemias and for all causes are shown by period from first employment and by year of death in table 5. The SMR for all causes of mortality in the most recent period of follow up (1991-7, SMR 83) was similar to that in preceding periods, indicating that inadequate tracing of deaths is not an issue in this study. Compared with national rates, the overall deficit in mortality from all leukaemias approached formal levels of significance (observed 111, expected 132.3, SMR 84, 95\% CI 69 to 101). The deficit in overall mortality from all causes 
Table 5 Standardised mortality ratios (SMRs) for the total study cohort ( $n=83$ 997) by period from hire and by year of death: study of United Kingdom electricity generation and transmission workers, 1973-97

\begin{tabular}{|c|c|c|c|c|c|c|c|c|}
\hline & \multicolumn{4}{|c|}{ All leukaemiat } & \multicolumn{4}{|c|}{ All causes } \\
\hline & $\mathrm{Obs}$ & $\operatorname{Exp}$ & $S M R$ & $(95 \% C I)$ & $\mathrm{Obs}$ & $\operatorname{Exp}$ & $S M R$ & $(95 \% C I)$ \\
\hline \multicolumn{9}{|c|}{ Period from hire $(\mathrm{y})$ : } \\
\hline $0-9$ & 6 & 11.8 & 51 & (19 to 110$)$ & 829 & 1133.1 & $73^{\star \star \star \star}$ & ( 68 to 78 ) \\
\hline $10-19$ & 34 & 32.1 & 106 & (73 to 148 ) & 3326 & 4024.7 & $83^{\star \star \star}$ & (80 to 85$)$ \\
\hline $20-29$ & 37 & 40.7 & 91 & (64 to 125 ) & 4864 & 5688.9 & $86^{\star \star \star}$ & (83 to 88 ) \\
\hline$\geqslant 30$ & 34 & 47.6 & $71^{\star}$ & (49 to 100 ) & 5826 & 7071.8 & $82^{\star \star \star}$ & (80 to 85$)$ \\
\hline \multicolumn{9}{|c|}{ Year of death: } \\
\hline $1973-80$ & 13 & 18.3 & 71 & (38 to 121$)$ & 1947 & 2467.3 & $79^{\star \star \star}$ & (75 to 82$)$ \\
\hline $1981-85$ & 27 & 24.7 & 109 & (72 to 159$)$ & 2794 & 3301.6 & $85^{\star \star \star}$ & (82 to 88 ) \\
\hline $1986-90$ & 29 & 31.7 & 92 & (61 to 132 ) & 3617 & 4312.5 & $84^{\star \star \star}$ & (81 to 87 ) \\
\hline 1991-97 & 42 & 57.6 & $73^{\star}$ & (53 to 99 ) & 6487 & 7837.0 & $83^{\star \star \star}$ & (81 to 85$)$ \\
\hline Total & 111 & 132.3 & 84 & (69 to 101$)$ & 14845 & 17918.4 & $83^{\star \star \star}$ & (82 to 84 ) \\
\hline
\end{tabular}

${ }^{\star} \mathrm{p}<0.05 ;{ }^{\star \star \star} \mathrm{p}<0.001$

†ICD-9 codes 204-208.

was highly significant (observed 14845 , expected 17 918.4, SMR 83, 95\% CI 82 to 84). Overall SMRs by type of leukaemia (not shown in table) were unexceptional (lymphoid leukaemia observed 35, expected 39.4, SMR 89, 95\% CI 62 to 124; myeloid leukaemia observed 68 , expected 81.9, SMR 83, 95\% CI 64 to 105; monocytic leukaemia observed 4, expected 2.1, SMR 191, 95\% CI 52 to 490; other and unspecified leukaemia observed 4, expected 8.8, SMR 45, 95\% CI 12 to 116 ).

POISSON REGRESSION

Mortalities for chronic lymphatic leukaemia, other leukaemia, all leukaemia, and all other

Table 6 Relative risks of mortality from chronic lymphatic leukaemia, other leukaemias, all leukaemias, and all other causes by levels of estimated cumulative magnetic field exposure in subcohort with work histories ( $n=79$ 972) (eight separate analyses): study of United Kingdom electricity generation and transmission workers, 1973-97

\begin{tabular}{|c|c|c|c|c|c|}
\hline $\begin{array}{l}\text { Cumulative } \\
\text { magnetic field } \\
\text { exposure }(\mu \text { T.y }) \dagger\end{array}$ & $n$ & $R R \ddagger$ & $(95 \% C I)$ & $R R S$ & $(95 \% C I)$ \\
\hline \multicolumn{6}{|c|}{ Chronic lymphatic leukaemiaף: } \\
\hline $0-2.4$ & 21 & 1.0 & & 1.0 & \\
\hline $2.5-4.9$ & 3 & 0.64 & (0.19 to 2.17$)$ & 0.69 & $(0.20$ to 2.39$)$ \\
\hline $5.0-9.9$ & 5 & 0.59 & (0.22 to 1.57$)$ & 0.67 & (0.24 to 1.89$)$ \\
\hline $10.0-19.9$ & 7 & 0.92 & (0.39 to 2.18$)$ & 1.07 & (0.41 to 2.78$)$ \\
\hline$\geqslant 20.0$ & 3 & 1.14 & (0.34 to 3.86$)$ & 1.40 & (0.39 to 4.98$)$ \\
\hline $\mathrm{p}$ Value for tren & & $\mathrm{p}>0.50$ & $>0.50$ & $\mathrm{p}>0.50$ & $1>0.50$ \\
\hline \multicolumn{6}{|c|}{ Other leukaemias $\neq \ddagger$ : } \\
\hline $0-2.4$ & 39 & 1.0 & & 1.0 & \\
\hline $2.5-4.9$ & 15 & $2.01^{\star}$ & (1.10 to 3.67$)$ & $2.03^{\star}$ & (1.09 to 3.79$)$ \\
\hline $5.0-9.9$ & 15 & 1.25 & (0.68 to 2.31$)$ & 1.30 & (0.68 to 2.47$)$ \\
\hline $10.0-19.9$ & 10 & 0.97 & (0.48 to 1.98$)$ & 1.04 & $(0.49$ to 2.21$)$ \\
\hline$\geqslant 20.0$ & 6 & 1.52 & (0.63 to 3.64$)$ & 1.63 & (0.66 to 4.01$)$ \\
\hline $\mathrm{p}$ Value for tren & & $\mathrm{p}>0.50$ & $>0.50$ & $\mathrm{p}=0.50$ & $=0.49$ \\
\hline \multicolumn{6}{|c|}{ All leukaemias 8 : } \\
\hline $0-2.4$ & 60 & 1.0 & & 1.0 & \\
\hline $2.5-4.9$ & 18 & 1.49 & (0.87 to 2.53$)$ & 1.53 & $(0.88$ to 2.65$)$ \\
\hline $5.0-9.9$ & 20 & 0.99 & (0.59 to 1.65$)$ & 1.05 & (0.61 to 1.81$)$ \\
\hline $10.0-19.9$ & 17 & 0.96 & (0.55 to 1.67$)$ & 1.05 & ( 0.58 to 1.90$)$ \\
\hline$\geqslant 20.0$ & 9 & 1.37 & (0.68 to 2.79$)$ & 1.53 & $(0.73$ to 3.18$)$ \\
\hline $\mathrm{p}$ Value for tren & & $\mathrm{p}>0.50$ & $>0.50$ & $\mathrm{p}>0.50$ & $=0.37$ \\
\hline \multicolumn{6}{|c|}{ All other causes 9 : } \\
\hline $0-2.4$ & 6,090 & 1.0 & & 1.0 & \\
\hline $2.5-4.9$ & 1,581 & $1.20^{\star \star \star}$ & (1.13 to 1.26$)$ & $1.07^{\star}$ & (1.01 to 1.13$)$ \\
\hline $5.0-9.9$ & 2,570 & $1.10^{\star \star \star}$ & (1.05 to 1.16$)$ & 0.96 & $(0.92$ to 1.01$)$ \\
\hline $10.0-19.9$ & 2,246 & $1.09^{\star \star}$ & (1.04 to 1.14 ) & 0.95 & $(0.90$ to 1.00$)$ \\
\hline$\geqslant 20.0$ & 701 & 0.94 & (0.87 to 1.02$)$ & $0.88^{\star \star}$ & $(0.81$ to 0.95$)$ \\
\hline \multicolumn{2}{|c|}{$\mathrm{p}$ Value for trendt† } & \multicolumn{2}{|c|}{$\mathrm{p}=0.04(+\mathrm{ve})$ and $=0.45$} & \multicolumn{2}{|c|}{$\mathrm{p}<0.001(-\mathrm{ve})$ and $<0.001(-\mathrm{ve})$} \\
\hline
\end{tabular}

${ }^{\star} \mathrm{p}<0.05 ;{ }^{\star \star \star} \mathrm{p}<0.001$

†One year refers to a working year, about 2508 hour shifts.

†Analysed simultaneously with sex and attained age.

\Analysed simultaneously with sex, attained age, calendar period, year of starting employment, and negotiating body. For levels, see table 4.

TSee footnote *table 4.

t†Linearly weighted $\mathrm{p}$ value for trend (five exposure categories scored 1-5) and dose weighted $\mathrm{p}$ value for trend (five exposure categories scored $0.36,3.67,7.24,13.93,38.53$ ), see text for details. Sign shows direction of any significant trend.

¥†See footnote trable 4 .

$\iint S$ ee footnote ttable 4.

ॠף See footnote Stable 4. causes are shown in table 6 for four categories of estimated cumulative occupational exposure to magnetic fields relative to the corresponding rates in the lowest (baseline) category of exposure $(<2.5 \mu$ T.y). Rate ratios (relative risks) in the left hand side of the table were obtained from four analyses (one analysis for each cause of death), each of which was adjusted for age and sex. Rate ratios in the right hand side of the table were obtained from a further four analyses, each of which was adjusted for age, sex, calendar period, year of starting employment, and negotiating body. Only one of the point estimates of risk shown for chronic lymphatic leukaemia, other leukaemia, and all leukaemia was significantly different from unity (lowest exposed category for other leukaemia), and there were no significant trends of risk increasing with exposure. When adjusted for age and sex only, there was a significant positive linearly weighted trend $(p=0.04)$ for risks from all causes other than leukaemia increasing with exposure to magnetic fields, and a nonsignificant trend $(p=0.45)$ for the corresponding dose weighted test. Further adjustment produced highly significant negative trends $(p<0.001)$ for both trend tests, although most point estimates of risk were close to unity. Negotiating body (an indicator of socioeconomic status) was an important predictor of general mortality (not shown in table 6) and further analyses (also not shown) indicated that it was the inclusion of this variable in the model which was having most influence on the differences between the two sets of relative risks for all causes other than leukaemia. Further adjustment for employment (still employed or left employment) and period of follow up did not eliminate the highly significant negative trend shown for all causes other than leukaemia (not shown in table 6). This negative trend was not dependent on a single category of deaths as further analyses showed negative trends for diseases of the circulatory system, all neoplasms, accidents and suicide, and for all other causes combined.

Corresponding findings for acute myeloid leukaemia and chronic myeloid leukaemia are shown in table 7 (presentation follows the style of table 6). None of the point estimates of risk shown for acute myeloid leukaemia and chronic myeloid leukaemia was significantly 
different from unity, and there were no significant trends of risk increasing with exposure.

Mortalities from chronic lymphatic leukaemia, other leukaemia, all leukaemia, and all other causes are shown in table 8 for four categories of estimated cumulative occupational exposure to magnetic fields received in the most recent 5 years relative to the corresponding rates in the lowest (baseline) category of

Table 7 Relative risks of mortality from acute myeloid leukaemia and chronic myeloid leukaemia by levels of estimated cumulative magnetic field exposure in subcohort with work histories ( $n=79$ 972) (four separate analyses): study of United Kingdom electricity generation and transmission workers, 1973-97

\begin{tabular}{|c|c|c|c|c|c|}
\hline $\begin{array}{l}\text { Cumulative magnetic } \\
\text { field exposure }(\mu T . y)^{*}\end{array}$ & $n$ & $R R t$ & $(95 \% C I)$ & $R R \ddagger$ & $(95 \% C I)$ \\
\hline \multicolumn{6}{|c|}{ Acute myeloid leukaemia $\$:$} \\
\hline $0-2.4$ & 25 & 1.0 & & 1.0 & \\
\hline $2.5-4.9$ & 7 & 1.49 & (0.64 to 3.48$)$ & 1.51 & (0.64 to 3.62$)$ \\
\hline $5.0-9.9$ & 8 & 1.06 & ( 0.47 to 2.40$)$ & 1.02 & (0.43 to 2.43$)$ \\
\hline $10.0-19.9$ & 6 & 0.92 & $(0.37$ to 2.30$)$ & 0.84 & ( 0.32 to 2.20$)$ \\
\hline$\geqslant 20.0$ & 3 & 1.20 & $(0.36$ to 4.04$)$ & 1.16 & (0.33 to 4.02$)$ \\
\hline $\mathrm{p}$ Value for trend & & $p>0$. & $\mathrm{nd}>0.50$ & $p>0.5$ & nd $>0.50$ \\
\hline \multicolumn{6}{|c|}{ Chronic myeloid leukaemia ${ }^{\star \star}$ : } \\
\hline $0-2.4$ & 9 & 1.0 & & 1.0 & \\
\hline $2.5-4.9$ & 4 & 2.12 & $(0.65$ to 6.93$)$ & 1.60 & (0.47 to 5.38$)$ \\
\hline $5.0-9.9$ & 4 & 1.27 & $(0.38$ to 4.21$)$ & 0.97 & (0.28 to 3.38$)$ \\
\hline $10.0-19.9$ & 2 & 0.72 & $(0.15$ to 3.42$)$ & 0.63 & (0.13 to 3.16$)$ \\
\hline$\geqslant 20.0$ & 1 & 0.96 & $(0.12$ to 7.72$)$ & 0.81 & (0.10 to 6.76$)$ \\
\hline $\mathrm{p}$ Value for trend & & \multicolumn{2}{|c|}{$p>0.50$ and $>0.50$} & \multicolumn{2}{|c|}{$\mathrm{p}>0.50$ and $>0.50$} \\
\hline
\end{tabular}

^See footnote trable 6 .

†Analysed simultaneously with sex and attained age.

¥Analysed simultaneously with sex, age, calendar period, year of starting employment, and negotiating body. For levels, see table 4.

\Any part of death certificate coded to ICD-9 205.0.

ๆSee footnote + ttable 6 .

${ }^{\star \star}$ Any part of death certificate coded to ICD-9 205.1

Table 8 Relative risks of mortality from chronic lymphatic leukaemia, other leukaemias, all leukaemias and all other causes by levels of estimated magnetic field exposure received in preceding 5 years in subcohort with work histories $(n=79$ 972) (eight separate analyses): study of United Kingdom electricity generation and transmission workers, 1973-94

\begin{tabular}{|c|c|c|c|c|c|}
\hline $\begin{array}{l}\text { Magnetic field } \\
\text { exposure receive } \\
\text { in preceding } 5 \\
\text { years }(\mu T . y) t\end{array}$ & $n$ & $R R \ddagger$ & $(95 \% C I)$ & $R R \int$ & $(95 \% C I)$ \\
\hline \multicolumn{6}{|c|}{ Chronic lymphatic leukaemiaq: } \\
\hline Zero & 23 & 1.0 & & \multicolumn{2}{|l|}{1.0} \\
\hline $0.01-0.49$ & 4 & 1.47 & (0.56 to 3.86$)$ & 1.43 & (0.53 to 3.87$)$ \\
\hline$\geqslant 0.50$ & 1 & 0.32 & (0.04 to 2.42 ) & 0.30 & (0.04 to 2.32$)$ \\
\hline \multicolumn{2}{|c|}{$\mathrm{p}$ Value for trend $+\dagger$} & \multicolumn{2}{|c|}{$\mathrm{p}=0.49$ and $=0.46$} & \multicolumn{2}{|c|}{$\mathrm{p}=0.44$ and $=0.44$} \\
\hline \multicolumn{6}{|c|}{ Other leukaemiasł‡: } \\
\hline Zero & 45 & 1.0 & & 1.0 & \\
\hline $0.01-0.49$ & 9 & 1.17 & (0.59 to 2.31$)$ & 1.16 & (0.58 to 2.32$)$ \\
\hline $0.50-1.99$ & 6 & 1.31 & (0.58 to 2.96$)$ & 1.38 & (0.60 to 3.16$)$ \\
\hline $2.0-4.99$ & 5 & 1.63 & (0.68 to 3.91$)$ & 1.72 & (0.71 to 4.15$)$ \\
\hline$\geqslant 5.0$ & 2 & 1.08 & (0.26 to 4.51$)$ & 1.04 & $(0.25$ to 4.41$)$ \\
\hline $\mathrm{p}$ Value for & adt† & $\mathrm{p}=0.32 \mathrm{a}$ & .50 & $\mathrm{p}=0.31 \mathrm{a}$ & 0.50 \\
\hline \multicolumn{6}{|c|}{ All leukaemias $₫ \oint$ : } \\
\hline Zero & 68 & 1.0 & & 1.0 & \\
\hline $0.01-0.49$ & 13 & 1.27 & (0.72 to 2.22$)$ & 1.24 & (0.70 to 2.19$)$ \\
\hline $0.50-1.99$ & 6 & 0.99 & (0.45 to 2.19 ) & 1.02 & (0.46 to 2.28$)$ \\
\hline $2.0-4.99$ & 6 & 1.46 & $(0.66$ to 3.24$)$ & 1.52 & (0.68 to 3.40$)$ \\
\hline$\geqslant 5.0$ & 2 & 0.82 & (0.20 to 3.40$)$ & 0.81 & (0.20 to 3.39$)$ \\
\hline \multicolumn{2}{|c|}{$\mathrm{p}$ Value for trend $+\dagger$} & \multicolumn{2}{|c|}{$\mathrm{p}>0.50$ and $>0.50$} & \multicolumn{2}{|c|}{$\mathrm{p}>0.50$ and $>0.50$} \\
\hline \multicolumn{6}{|c|}{ All other causes $1 \Phi:$} \\
\hline Zero & 7521 & 1.0 & & 1.0 & \\
\hline $0.01-0.49$ & 1163 & 1.05 & (0.99 to 1.11$)$ & $0.94^{\star}$ & (0.89 to 1.00$)$ \\
\hline $0.50-1.99$ & 675 & 0.93 & (0.86 to 1.01$)$ & $0.80^{\star \star \star}$ & (0.74 to 0.86$)$ \\
\hline $2.0-4.99$ & 374 & $0.82^{\star \star \star}$ & (0.74 to 0.91$)$ & $0.71^{\star \star \star}$ & (0.64 to 0.79$)$ \\
\hline$\geqslant 5.0$ & 187 & $0.81^{\star \star}$ & (0.70 to 0.93$)$ & $0.70^{\star \star \star}$ & (0.60 to 0.80$)$ \\
\hline \multicolumn{2}{|c|}{$\mathrm{p}$ Value for trendt† } & \multicolumn{2}{|c|}{$\mathrm{p}<0.001(-\mathrm{ve})$ and $<0.001(-\mathrm{ve})$} & \multicolumn{2}{|c|}{$\mathrm{p}<0.001(-\mathrm{ve})$ and $<0.001$ (-ve } \\
\hline
\end{tabular}

${ }^{\star} \mathrm{p}<0.05 ;{ }^{\star \star} \mathrm{p}<0.01 ;{ }^{\star \star \star} \mathrm{p}<<0.001$

†See footnote trable 6 .

†Analysed simultaneously with sex and attained age.

\Analysed simultaneously with sex, attained age, calendar period, year of starting employment, and negotiating body. For levels, see table 4.

TSee footnote *table 4.

t+Linearly weighted $\mathrm{p}$ value for trend (five exposure categories scored 1-5) and dose weighted $\mathrm{p}$ value for trend (five exposure categories scored $0.0,0.19,1.14,3.16,11.40$ ), see text for details. Sign shows direction of any significant trend.

¥¥See footnote trable 4 .

$\iint S$ ee footnote ttable 4

ॠף See footnote Stable 4. zero exposure. The presentation of results follows the style of table 6 , although the closing date of the survey is now placed at $30 \mathrm{March}$, 1994 (end of exposure assessments). None of the point estimates of risk shown for chronic lymphatic leukaemia, other leukaemia, and all leukaemia was significantly different from unity, and there were no significant trends of risk increasing with exposure. A highly significant negative trend $(p<0.001)$ was found for risks from all causes other than leukaemia and recent exposure to magnetic fields, both when adjusted for age and sex only and when further adjustments were carried out.

Corresponding findings for acute myeloid leukaemia and chronic myeloid leukaemia are shown in table 9. These analyses were based on few exposed cases, although none of the point estimates of risk shown was significantly different from unity, and there were no significant trends of risk increasing with exposure.

Information on leukaemia subtypes obtained from the survey death certificates was compared with corresponding information obtained from cancer registration particulars. Of the 39 deaths from chronic lymphatic leukaemia, corresponding registration particulars were obtained for 31 subjects of which 29 $(93.5 \%)$ were recorded as chronic lymphatic leukaemia. Of the 49 deaths from acute myeloid leukaemia, corresponding registration particulars were obtained for 40 subjects of which $35(87.5 \%)$ were recorded as acute myeloid leukaemia. Registration particulars were obtained for all 20 deaths with chronic myeloid leukaemia; all were registered as chronic myeloid leukaemia.

\section{Discussion}

This large cohort of United Kingdom electricity generation and transmission workers did not have increased mortalities from leukaemia, on the basis of comparisons with national rates. Also there were no indications of risks of leukaemia increasing with increasing exposure to magnetic fields, irrespective of which subtype of leukaemia was considered and irrespective of whether lifetime or recent exposure was considered.

The style of exposure assessment recognises that the main source of exposure to magnetic fields in a power station is proximity to the main generator connections, and consequently, that the physical layout of departments in power stations will be highly relevant. Also, the assessments recognise that exposures will depend on the variable power output of the station. In short, the assessments have used the physics of exposure to magnetic fields as a starting point. Some early validation work on the power station model has already been completed (Renew DC, personal communication). Mean exposures to magnetic fields have been calculated for 29 job-facility combinations; these means were based on some 4200 personal full shift magnetic field measurements taken in the period January to July 1999, for employees at three power stations. There was a significant correlation $(p<0.05)$ between the predicted and measured mean fields. It is 
Table 9 Relative risks of mortality from acute myeloid leukaemia and chronic myeloid leukaemia by levels of estimated magnetic field exposure received in preceding 5 years in subcohort with work histories ( $n=79$ 972) (four separate analyses): study of United Kingdom electricity generation and transmission workers, 1973-94

\begin{tabular}{|c|c|c|c|c|c|}
\hline $\begin{array}{l}\text { Magnetic field exposure } \\
\text { received in preceding } 5 \\
\text { years }(\mu \text { T.y })^{\star}\end{array}$ & $n$ & $R R t$ & $(95 \% C I)$ & $R R \ddagger$ & $(95 \% C I)$ \\
\hline \multicolumn{6}{|c|}{ Acute myeloid leukaemia』: } \\
\hline Zero & 28 & 1.0 & & 1.0 & \\
\hline $0.01-0.49$ & 5 & 1.14 & (0.47 to 2.74$)$ & 1.14 & (0.47 to 2.78$)$ \\
\hline $0.5-1.99$ & 3 & 0.90 & ( 0.27 to 3.02$)$ & 0.98 & (0.29 to 3.34$)$ \\
\hline $2.0-4.99$ & 2 & 0.86 & $(0.20$ to 3.69$)$ & 0.96 & $(0.22$ to 4.18$)$ \\
\hline$\geqslant 5.0$ & 1 & 0.83 & $(0.11$ to 6.20$)$ & 0.93 & $(0.12$ to 7.05$)$ \\
\hline $\mathrm{p}$ Value for trend & & $\mathrm{p}>0$ & $\mathrm{~d}>0.50$ & $\mathrm{p}>0$ & $\mathrm{~d}>0.50$ \\
\hline \multicolumn{6}{|c|}{ Chronic myeloid leukaemia $^{\star \star}$ : } \\
\hline Zero & 11 & 1.0 & & 1.0 & \\
\hline $0.01-0.49$ & 2 & 0.92 & $(0.21$ to 4.10$)$ & 0.73 & $(0.16$ to 3.31$)$ \\
\hline $0.5-1.99$ & 1 & 0.75 & (0.09 to 5.89$)$ & 0.56 & $(0.07$ to 4.52$)$ \\
\hline $2.0-4.99$ & 1 & 1.13 & $(0.14$ to 8.99 & 0.84 & $(0.10$ to 6.74$)$ \\
\hline$\geqslant 5.0$ & 1 & 2.29 & (0.28 to 18.46$)$ & 1.40 & (0.17 to 11.49$)$ \\
\hline $\mathrm{p}$ Value for trend & & \multicolumn{2}{|c|}{$\mathrm{p}>0.50$ and $=0.44$} & \multicolumn{2}{|c|}{$\mathrm{p}>0.50$ and $>0.50$} \\
\hline
\end{tabular}

$\star$ See footnote trable 6 .

†Analysed simultaneously with sex and attained age.

¥Analysed simultaneously with sex, attained age, calendar period, year of starting employment, and negotiating body. For levels, see table 4 .

§See footnote \$table 7 .

TSee footnote ${ }^{\star \star}$ table 8 .

${ }^{\star \star}$ See footnote ${ }^{\star \star}$ table 7 . significant. The negative trend shown for this disease grouping and lifetime occupational exposure to magnetic fields after adjustment for socioeconomic category (negotiating body) is probably due to a selection effect. A particular form of the survivor population effect may be present. Perhaps workers who stay in the industry doing jobs with higher exposures have to be fitter than workers remaining in other jobs. It does not follow that any such selection effect would operate in the same way on risks of leukaemia; it may be irrelevant, or fitter people might even be at a higher risk of leukaemia.

Leukaemia risks relative to estimated cumulative exposure to magnetic fields have been studied in other cohorts of electric utility workers. The Southern California Edison Study $^{3}$ and the United States Five Utility Study ${ }^{5}$ both provided findings consistent with those reported here. The Canada-France study ${ }^{4}$ provided positive findings, particularly for acute myeloid leukaemia, but given the results from the other studies, these positive findings may well be due to chance.

The study protocol had proposed significant positive trends of risk of leukaemia with exposure as forming the key evidence for any leukaemogenic effects of exposure to magnetic fields. In the event, no such trends have been found. This large cohort study provides no evidence that United Kingdom electricity generation and transmission workers have an excess risk of leukaemia as a consequence of occupational exposure to magnetic fields.

Some limitations have to be attached, however, to our use of the exposure assessments. It has been necessary to assume that a particular job category is associated with the same pattern of departmental working in different power stations and in different periods. Also, exposures associated with employment before 1 April 1952, are not assessed, and first known employment details are assumed to apply to all employment with the CEGB before 1971. Concern has been expressed previously about the use of data from death certificates to investigate risks for leukaemia subtypes. ${ }^{10}$ For this particular survey, however, the comparison with cancer registration data suggests that no important bias could have been introduced by the use of death certificate data, particularly for chronic lymphatic leukaemia and chronic myeloid leukaemia.

The study cohort comprises an entry (inception) cohort and a survivor population. Currently, the survivor population subcohort contributes about $85 \%$ of the deaths from all causes currently available for analysis. It would have been preferable to have had a study in which the entry cohort dominated the study findings. Analyses for all causes of death other than leukaemia were carried out so that the usefulness of the explanatory variables could be assessed. It seemed highly unlikely that exposure to magnetic fields could have a discernible influence on mortality in general, so that a significant negative or positive trend for this overall disease grouping might indicate that some selection or social class effect was not being adjusted for, although with such large numbers of deaths available for this analysis, small differences in risk ratios can be highly
We thank Mr Peter Brodie, British Energy, for supplying copies of the study databases, the Office for National Statistics for follow up details, Mr Gordon Neale and Mr Tony Lounsbach for Renew and other members of the EMF Research Section, National Grid Company, for the (extraordinarily) detailed exposure assessments, the pensions and human resources departments of the participating companies for solving data queries, and Margaret Williams for word processing. Survey costs were defrayed by a research award from member companies of the Electricity Association.

1 Milham S. Mortality from leukaemia in workers exposed to electric and magnetic fields. N Engl f Med 1982;307:249.

2 Lin RS, Dischinger PC, Conde J, et al. Occupational exposure to electromagnetic fields and the occurrence of brain

3 Sahl JD, Kelsh MA, Greenland S. Cohort and nested case control studies of haemopoetic cancer and brain cancer among electric utility workers. Epidemiology 1993;4:10414 .

4 Theriault G, Goldberg M, Miller AB, et al. Cancer risks associated with occupational exposure to magnetic fields among electric utility workers in Ontario and Quebec, Canada, and France: 1970-89. Am F Epidemiol 1994;139: 550-72.

5 Savitz DA, Loomis DP. Magnetic field exposure in relation to leukaemia and brain cancer mortality among electric utility workers. Am f Epidemiol 1995;141:123-34.

6 Harrington JM, McBride DI, Sorahan T, et al. Occupational Harrington JM, McBride DI, Sorahan T, et al. Occupational
exposure to magnetic fields in relation to mortality from exposure to magnetic fields in relation to mortality from
brain cancer among electricity generation and transmission brain cancer among electricity generation and

7 Johansen C, Olsen JH. Risk of cancer among Danish utility workers. Am f Epidemiol 1998;147:548-55.

8 National Radiological Protection Board. Electromagnetic fields and the risk of cancer: report of an advisory group on nonionising radiation. Chilton, Oxfordshire: NRPB, 1992. (Doc NRPB 3 No 1.)

9 Kheifets LI, Afifi AA, Buffler PA, et al. Occupational electric and magnetic field exposure and leukaemia: a metaanalysis. F Occup Environ Med 1997;39:1074-91.

10 National Institute of Environmental Health Sciences. Assessment of health effects from exposure to power-line frequency electric and magnetic fields. Working Group report. rrequency electric and magnetic fields. Working Group
Research Triangle Park, NC, USA: NIEHS, 1998. power frequency magnetic field for electricity generation and transmission workers. Leatherhead, UK: National Grid Co, 2001 interpretation and classification of work histories, Dr David tumours. F Occup Med 1985;27:413.

11 Renew DC. A method for assessing occupational exposure to 
12 Coleman M, Douglas A, Hermon C, et al. Cohort study andysis with a Fortro A 1986;15:134-7.

13 Epicure. Seattle, USA: Hirosoft International Corporation, 1988.
14 Breslow NE, Day NE. Statistical methods in cancer research. Vol II - The design and analysis of cohort studies. Lyon: International Agency for Research on Cancer, 1987. (IARC Sci Publ No 82.)

\section{1st Asia Pacific Forum on Quality Improvement in Health Care. Three day conference \\ Wednesday 19 to Friday 21 September 2001 Sydney, Australia}

We are delighted to announce this forthcoming conference in Sydney.

Delegate enquiries are welcome.

The themes of the Forum are:

- Improving patient safety

- Leadership for improvement

- Consumers driving change

- Building capacity for change: measurement, education, and human resources

- The context: incentives and barriers for change

- Improving health systems

- The evidence and scientific basis for quality improvement.

Presented to you by the BMJ Publishing Group (London, UK) and Institute for Healthcare Improvement (Boston, USA), with the support of the the Commonweatlh Department of Health and Aged Care (Australia), Safety and Quality Council (Australia), NSW Health (Australia), and Ministry of Health (New Zealand).

For more information contact: quality@bma.org.uk or fax +44(0) 73836869 